\title{
Local Homogeneity of Cell Cycle Length in Developing Mouse Cortex
}

\author{
Li Cai, ${ }^{1,2}$ Nancy L. Hayes, ${ }^{1}$ and Richard S. Nowakowski ${ }^{1,2}$ \\ ${ }^{1}$ Department of Neuroscience and Cell Biology and 2Physiology and Neurobiology Graduate Program, \\ Rutgers University and University of Medicine and Dentistry of New Jersey-Robert Wood Johnson Medical School, \\ Piscataway, New Jersey 08854
}

\begin{abstract}
We have measured the amount of variation in the length of the cell cycle for cells in the pseudostratified ventricular epithelium (PVE) of the developing cortex of mice on embryonic day 14. Our measurements were made in three cortical regions (i.e., the neocortex, archicortex, and periarchicortex) using three different methods: the cumulative labeling method (CLM), the percent labeled mitoses (PLM) method, and a comparison of the time needed for the PLM to ascend from 0 to $100 \%$ with the time needed for the PLM to descend from 100 to $0 \%$. These 3 different techniques provide different perspectives on the cytokinetic parameters. Theoretically, CLM gives an estimate for a maximum value of the total length of the cell cycle $\left(T_{C}\right)$, whereas PLM gives an estimate of a minimum value of $T_{C}$. The difference between these two estimates indicates that the range for $T_{C}$ is $\pm 1 \%$ of the mean $\mathrm{T}_{\mathrm{C}}$ for periarchicortex, $\pm 7 \%$ for neocortex, and $\pm 8 \%$ for archicortex. This was confirmed by a lengthening of the PLM descent time in comparison with its ascent time. The sharpness of the transitions and the flatness of the plateau
\end{abstract}

of the PLM curves indicate that 99\% of the proliferating cells are within this narrow estimated range for $\mathrm{T}_{\mathrm{C}}$; hence, only $\sim 1 \%$ deviate outside of a relatively restricted range from the average $\mathrm{T}_{\mathrm{C}}$ of the population. In the context of the possible existence within the cortical PVE of two populations with markedly dissimilar cell cycle kinetics from the mean, one such population must comprise $\sim 99 \%$ of the total population, and the other, if it exists, is only $\sim 1 \%$ of the total. This seems to be true for all three cortical regions. The narrow range of $\mathrm{T}_{\mathrm{C}}$ indicates $\mathrm{a}$ homogeneity in the cell cycle length for proliferating cells in three different cortical regions, despite the fact that progenitor cells of different lineages may be present. It further predicts the existence of almost synchronous interkinetic nuclear movements of the proliferating cells in the ventricular zone during early development of the cerebral cortex.

Key words: neuronogenesis; mouse; cell proliferation; ventricular zone; $S$ phase labeling; bromodeoxyuridine
In the mammalian cortex, most neuronogenesis occurs in a pseudostratified ventricular epithelium (PVE) that occupies the ventricular zone adjacent to the lateral ventricle. Within the PVE, proliferating cells undergo interkinetic nuclear migration such that the position of the nucleus correlates with the phase of the cell cycle. DNA synthesis or S phase occurs in the outer half of the ventricular zone, and mitosis occurs at the ventricular surface (Angevine and Sidman, 1961; Rakic, 1972; Caviness and Sidman, 1973; Takahashi et al., 1995a). Thus, during a single cell cycle, the nucleus of a proliferating cell moves from the ventricular surface outward during $G_{1}$ and returns to the ventricular surface during $S$ and $G_{2}$. The time required for a single cell cycle has been measured in previous studies of cell cycle kinetics that have exploited both the percent labeled mitoses (PLM) method (Hoshino et al., 1973; Cai et al., 1993; Takahashi et al., 1993; Reznikov and van der Kooy, 1995) and also the cumulative labeling method (CLM; Waechter and Jaensch, 1972; Miller and Nowakowski, 1988; Nowakowski et al., 1989; Cai et al., 1993; Takahashi et al., 1992, 1993, 1995a; Reznikov and van der Kooy, 1995). Taken together, these studies have measured the lengths of each cell cycle during the neuronogenetic period and demonstrated that the cell cycle

\footnotetext{
Received Aug. 5, 1996; revised Dec. 17, 1996; accepted Dec. 20, 1996.

Supported by National Institutes of Health Grants NS28061 and NS33443 and NASA Grant NAG2-950.

Correspondence should be addressed to Dr. Richard S. Nowakowski, Department of Neuroscience and Cell Biology, UMDNJ-Robert Wood Johnson Medical School, Piscataway, NJ 08854.

Copyright (C) 1997 Society for Neuroscience $\quad 0270-6474 / 97 / 172079-09 \$ 05.00 / 0$
}

lengthens as development proceeds. Relatively little attention, however, has been paid to the variation of cell cycle time at any particular stage of development. In this respect, using cumulative labeling with 5-bromo-2'-deoxyuridine (BUdR), Nowakowski et al. (1989) and Takahashi et al. (1993) found that the labeling index (LI) increases linearly until all proliferating cells are labeled. This linearity indicates that, in terms of the length of the cell cycle $\left(\mathrm{T}_{\mathrm{C}}\right)$ and the length of the $\mathrm{S}$ phase $\left(\mathrm{T}_{\mathrm{S}}\right)$, the cells of the PVE constitute a single population and move through the cell cycle at approximately the same rate. Specifically, it has been estimated from these results that $80-90 \%$ of the proliferating cells have cytokinetic parameters within $\sim 10 \%$ of the mean (Nowakowski et al., 1989). Thus, it remains possible that as many as $10-20 \%$ of the PVE cells have significantly different cytokinetic parameters. To investigate this possibility, we have measured the range of times (i.e., the maximum and minimum time needed for cells to complete a single cell cycle) and the variation in time required for a labeled cohort of cells to enter versus leave $M$ phase, and estimated the purity of the proliferating population in terms of $\mathrm{T}_{\mathrm{C}}$.

The present analysis is focused on the PVE of three different subdivisions of the E14 mouse cortex: the neocortex, archicortex, and periarchicortex (Fig. 1). These three subdivisions differ clearly in their proliferative population. In the archicortex, there is only a single proliferative population (Nowakowski and Rakic, 1981), the PVE. In the neocortex and periarchicortex, in addition to the PVE, there is a secondary proliferative population (SPP), which is 


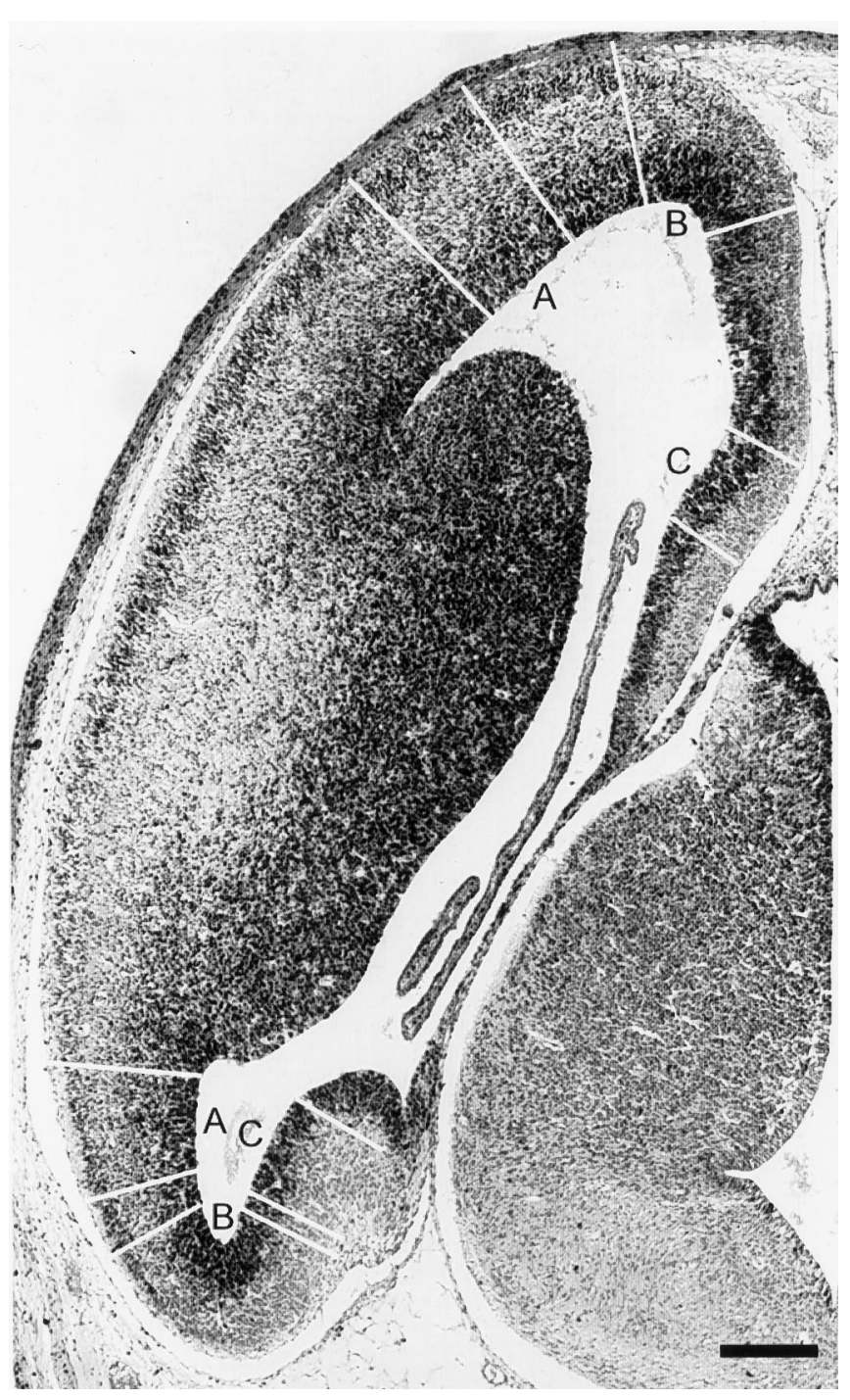

Figure 1. A section through a cerebral hemisphere of the E14 mouse to illustrate the location of the cortical subdivisions analyzed. The three areas can be distinguished by their unique structure and their location and are indicated by white lines spanning the pallium and by letters in the lateral ventricles. The neocortical region analyzed was in the lateral wall $(A)$; the archicortical region analyzed was in the hippocampal anlage in the medial wall $(C)$; and the periarchicortical region analyzed occupied the curve near the rostral or caudal tip of the brain $(B)$. On this approximately horizontal section, the areas analyzed are sectioned twice, once in the rostral portion of the cerebrum (top) and once in the caudal portion of the cerebrum (bottom). The areas selected for analysis always included all three cortical areas on a single section and subtended $200 \mu \mathrm{m}$ along the ventricular surface. Scale bar, $200 \mu \mathrm{m}$.

believed to be the source of most neuroglial cells (Takahashi et al., 1995b). Because there is no SPP in the archicortex, both neuronal and glial lineages presumably arise from the PVE (Nowakowski and Rakic, 1981). In addition, the PVE of neocortex probably contains not only the progenitors of neurons but also the progenitors of proliferative radial glial cells and perhaps other glial cells (Levitt et al., 1981; Nowakowski and Rakic, 1981; Caviness, 1982; Misson et al., 1988a,b). Thus, it is likely that there are progenitor cells of different lineages (e.g., neuronal and glial) in the PVE and that their proportions differ in various cortical subdivisions. Thus, the results of the present study address the general issue of whether the proliferative populations giving rise to different lineages in the PVE have different or similar cell cycle parameters.

\section{MATERIALS AND METHODS}

Animals. Timed-pregnant CD-1 mice were purchased from Charles River Laboratories (Wilmington, MA) and maintained on a $12 \mathrm{hr} / 12 \mathrm{hr}$ (7:00 A.M. to 7:00 P.M.) light/dark schedule from the time of arrival until the time of the experiment. Pregnancies were timed from the day on which a vaginal plug was detected, designated as E0. All experiments were initiated at 8:00 AM on E14.

Cumulative labeling with BUdR. The CLM with BUdR has been described in detail elsewhere (Nowakowski et al., 1989). On E14, dams received i.p. injections of BUdR $(50 \mu \mathrm{g} / \mathrm{gm}$ body weight in $0.9 \% \mathrm{NaCl}$, $0.007 \mathrm{~N} \mathrm{NaOH}$ ) at $2 \mathrm{hr}$ intervals over a total period of $12 \mathrm{hr}$, beginning at 8:00 A.M. Thirty min after each of the BUdR injections, selected dams were deeply anesthetized with $4 \%$ chloral hydrate, and the fetuses were removed by hysterotomy and fixed by immersion in $4 \%$ phosphate buffered paraformaldehyde, $\mathrm{pH}$ 7.4. A total of 18 litters were collected at a total of 7 time points.

PLM method. On E14, dams received a single i.p. injection of BUdR at 8:00 AM. Litters were harvested as described above at intervals ranging from $30 \mathrm{~min}$ to $2 \mathrm{hr}$ over a total period of $17.5 \mathrm{hr}$. A total of 35 litters at 25 time points were collected. Note that at certain critical time points, such as near the beginning and end of the rise time and fall time of the mitotic labeling index (MLI), the interval between the collection times was decreased, and the number of litters used per time point was increased to provide optimal temporal resolution. As a result, the PLM data have a resolution of $\sim 0.5 \mathrm{hr}$.

Histology. All embryos were staged (Theiler, 1972) immediately after hysterotomy; specimens younger or older than E14 were excluded from this analysis. Subsequently, tissue was processed for BUdR immunohistochemistry according to a modification of Nowakowski et al. (1989). The dorsal skull was removed, and the brains were post-fixed in situ overnight, washed, dehydrated through a graded ethanol series, cleared, and embedded in paraplast. The brains were sectioned serially at $4 \mu \mathrm{m}$ in a plane approximating a horizontal section and mounted on glass slides pretreated with 3-aminopropyl-triethoxysilane. Slides containing both rostral and caudal portions of the archicortex were deparaffinized, treated with $0.1 \%$ trypsin to disrupt the cross linkage of tissue proteins, and with $2 \mathrm{~N}$ $\mathrm{HCl}$ to produce single-stranded DNA, then processed for immunohistochemical visualization of BUdR using an antibody against single-stranded DNA (Becton-Dickinson 1:75), a Vectastain Elite ABC kit (Mouse IgG), and $\mathrm{DAB}$ with cobalt-nickel color intensification; slides were counterstained with $1 \%$ basic fuchsin.

Nomenclature. The standard abbreviations for the lengths of the four phases of the cell cycle, i.e., $G_{1}, S, G_{2}$, and $M$ were used. When specific reference is made to the length of one of the phases it is used as a subscript for $T$ (representing "time"); thus, $T_{G 1}$ is the length of $G_{1}, T_{S}$ is the length of $S$, etc. For consistency, the abbreviation $T_{C}$ was used to refer to the length of the entire cell cycle. A table of these standard abbreviations was previously published (Nowakowski et al., 1989).

Analysis. Two to six fetuses from each litter were included in the analysis. For each specimen, a sector of $200 \mu \mathrm{m}$ along the ventricular surface was delineated in each of the three cortical areas (neocortex, archicortex, and "periarchicortex", see Fig. 1) in three to five nonadjacent sections. Archicortex was recognized by its position on the medial wall of the hemisphere and its lack of a subventricular zone; neocortex was recognized by its position on the lateral wall of the hemisphere and the presence of a small subventricular zone. Periarchicortex was arbitrarily defined as occupying the perimeter of the archicortex, and in this study probably included both incipient entorhinal and incipient cingulate cortex. For all three cortical areas, data from both rostral and caudal extents of the cortex were pooled to obtain enough labeled mitotic figures to perform the PLM method.

$C L M$. For each of the seven time points, a minimum of eight fetuses per time point were processed. However, data from some fetuses were not available as a result of technical artifacts (i.e., wrong plane of section, failure in immunohistochemical processing, etc.). Data were analyzed from all fetuses not excluded for technical reasons and were from a total of 18 litters containing 42 fetuses. At each time point, the data analyzed were obtained from at least four fetuses from at least two different litters. For each section, the positions of BUdR-labeled and unlabeled nuclei in each $200 \mu \mathrm{m}$ sector were recorded on drawings made with the aid of a camera lucida, and the numbers of each type of nuclei were counted. The design and interpretation of the CLM has been described in detail 

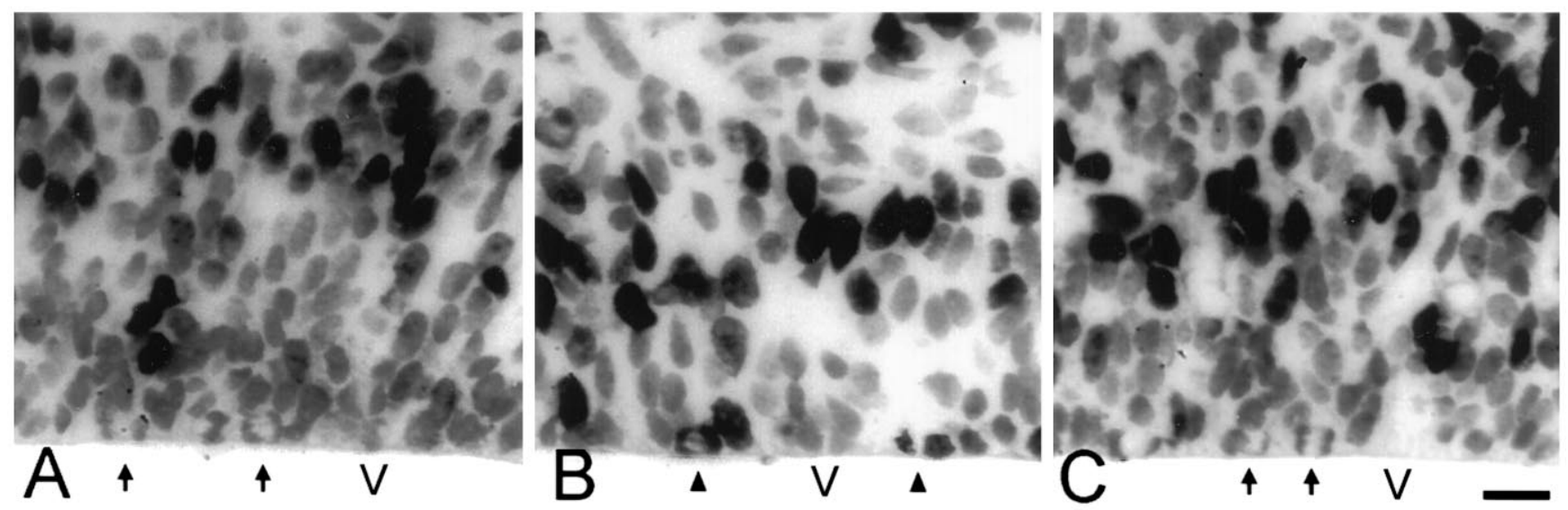

Figure 2. Photomicrographs of 4- $\mu \mathrm{m}$-thick horizontal sections through the neocortical PVE in the lateral region of the cerebral wall of E14 mice after in utero exposure to a single BUdR injection. $A$, Animal killed $1.0 \mathrm{hr}$ after injection, before the labeled cohort of cells has entered M phase. $B$, Animal killed $5.5 \mathrm{hr}$ after injection, well after the labeled cohort entered $\mathrm{M}$ phase. $C$, Animal killed $10.5 \mathrm{hr}$ after injection, when the labeled cohort had exited $\mathrm{M}$ phase. Unlabeled (arrows) and labeled (arrowheads) mitotic figures are located along the margin of the lateral ventricle. The tissue was processed for BUdR immunohistochemistry and lightly counterstained with basic fuchsin. $V$, Lateral ventricle. Scale bar, $20 \mu \mathrm{m}$.

Table 1. Cytokinetic parameters of the PVE in E14 mouse cortex as measured by CLM and PLM method

\begin{tabular}{|c|c|c|c|c|c|c|c|c|c|c|}
\hline \multirow[b]{2}{*}{$\begin{array}{l}\text { Cortical } \\
\text { subdivision }\end{array}$} & \multicolumn{3}{|c|}{ CLM } & \multicolumn{5}{|c|}{ PLM method } & \multirow[b]{2}{*}{$\begin{array}{l}\Delta \mathrm{T}_{\mathrm{C}} \\
(\mathrm{hr})\end{array}$} & \multirow[b]{2}{*}{$\begin{array}{l}\% \text { of } \\
\text { mean } \mathrm{T}_{\mathrm{C}}\end{array}$} \\
\hline & GF & $\begin{array}{l}\mathrm{T}_{\mathrm{C}} \\
(\mathrm{hr})\end{array}$ & $\begin{array}{l}\mathrm{T}_{\mathrm{S}} \\
(\mathrm{hr})\end{array}$ & $\begin{array}{l}\mathrm{T}_{\mathrm{C}} \\
(\mathrm{hr})\end{array}$ & $\begin{array}{l}\mathrm{T}_{\mathrm{S}} \\
(\mathrm{hr})\end{array}$ & $\begin{array}{l}\mathrm{T}_{\mathrm{M}} \\
(\mathrm{hr})\end{array}$ & $\begin{array}{l}\mathrm{T}_{\mathrm{G} 1} \\
(\mathrm{hr})\end{array}$ & $\begin{array}{l}\mathrm{T}_{\mathrm{G} 2} \\
(\mathrm{hr})\end{array}$ & & \\
\hline Neocortex & 0.8 & 14.0 & 3.7 & 12.3 & 6.5 & 1.2 & 3.7 & 0.9 & 1.7 & $13.3( \pm 6.7)$ \\
\hline Archicortex & 0.8 & 14.3 & 3.5 & 12.1 & 6.6 & 1.4 & 3.4 & 0.8 & 2.2 & $16.7( \pm 8.3)$ \\
\hline Periarchicortex & 0.9 & 12.4 & 2.4 & 12.2 & 6.5 & 1.3 & 3.6 & 0.8 & 0.2 & $1.5( \pm 0.7)$ \\
\hline
\end{tabular}

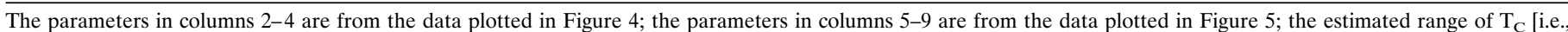

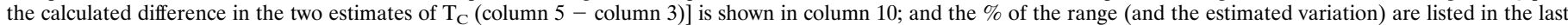
column.

previously (Nowakowski et al., 1989). In brief, cells of the PVE in S phase are labeled cumulatively by repeated exposures to BUdR until all proliferating cells have been labeled. The LI (i.e., the ratio of labeled nuclei to total nuclei) at each time point is plotted as a function of time after the first injection. The growth fraction (GF, i.e., the ratio of proliferating cells to the total number of cells in the population) and the values of $\mathrm{T}_{\mathrm{C}}$ and $\mathrm{T}_{\mathrm{S}}$ are then calculated as described previously (Nowakowski et al., 1989; Takahashi et al., 1992), using a nonlinear least squares fit that considers all of the data points.

PLM method. A total of 35 litters at 25 time points were collected. At least 2 fetuses were analyzed for each of the 25 time points. Because of technical limitations, specimens could be collected and processed for only 7-8 time points per experimental group; therefore, the data were collected in four experimental groups. Each experimental group was treated identically, except that the sacrifice times for the litters were varied for each experimental group so that the critical rise and fall times of the MLI plot (Fig. 5) would contain data from at least two and preferably three different time points. For each specimen, all labeled and unlabeled mitotic figures (Fig. 2), along the ventricular surface in each of the $200 \mu \mathrm{m}$ sectors, were counted in both right and left hemispheres of each brain. Mitotic figures of endothelial cells were excluded. A total of 10,219 mitotic figures in 66 fetuses were analyzed.

A single injection of BUdR labels a cohort of cells that are in S phase at the time of the injection. The cells of this cohort remain labeled as they progress through the cell cycle, and during $\mathrm{M}$ phase they are easily recognized as labeled mitotic figures. The MLI (i.e., the ratio of labeled mitotic figures to total mitotic figures) was calculated for each section and averaged for each fetus. Data for each fetus were then plotted, using a least squares fit that considers all of the data points, as a function of time after the BUdR injection, and the duration of all phases of the cell cycle were determined from this plot (Fig. 3) as follows: the time between injection of BUdR and the appearance of the first labeled mitotic figure is a measurement of $\mathrm{T}_{\mathrm{G} 2}$. An estimate of this time was determined from the $\mathrm{X}$-intercept of a linear least squares fit to the data points comprising the rising phase of the plots shown in Figure 5. The time required for the leading cells of the labeled cohort to enter M phase and MLI to reach $100 \%$ is $\mathrm{T}_{\mathrm{G} 2+\mathrm{M}}$. An estimate of this time was obtained from the $100 \%$ intercept of a linear least squares fit to the data lying on the ascending phase of the plots in Figure 5. MLI stays at $100 \%$ for a time approximately equal to $\mathrm{T}_{\mathrm{S}}-\mathrm{T}_{\mathrm{M}}$ and then decreases back to $0 \%$. When the leading cells of this same cohort reenter M phase, a second rise of MLI begins. $\mathrm{T}_{\mathrm{C}}$ is obtained by measuring the time interval between two corresponding points in sequential cell cycles (Kauffman, 1968; Hoshino et al., 1973; Steel, 1977; Reznikov and van der Kooy, 1995). $\mathrm{T}_{\mathrm{G} 1}$ is obtained by subtraction, $\mathrm{T}_{\mathrm{G} 1}=\mathrm{T}_{\mathrm{C}}-\left(\mathrm{T}_{\mathrm{S}}+\mathrm{T}_{\mathrm{G} 2}+\mathrm{T}_{\mathrm{M}}\right)$.

Comparison of the rise time and fall time of the MLI. The cell cycle length increases as development proceeds. To determine the variation of $\mathrm{T}_{\mathrm{C}}$ within a single cell cycle, we compared the time needed for the MLI to rise from 0 to $100 \%$ with the time needed for the MLI to fall from 100 to $0 \%$. The difference between the fall time and rise time is a measurement of the variability of lengthening within a single cell cycle because of the mixing of fast cycling unlabeled cells with slowly cycling labeled cells.

\section{RESULTS}

The cell cycle parameters in subdivisions of developing cortex of E14 mouse as measured by both the CLM (Fig. 4) and the PLM method (Fig. 5) are summarized in Table 1.

\section{Cell cycle parameters as determined by the CLM}

In each of the three cortical subdivisions analyzed, LI plotted as a function of time increased linearly until the GF was labeled (Fig. 4), after which LI no longer increased. At E14, GF was 0.82 in the neocortex, 0.82 in the archicortex, and 0.87 in the periarchicortex. $\mathrm{T}_{\mathrm{C}}$ and $\mathrm{T}_{\mathrm{S}}$ were calculated from the graphs based on the following two relationships: (1) the time required to label the GF, i.e., the 


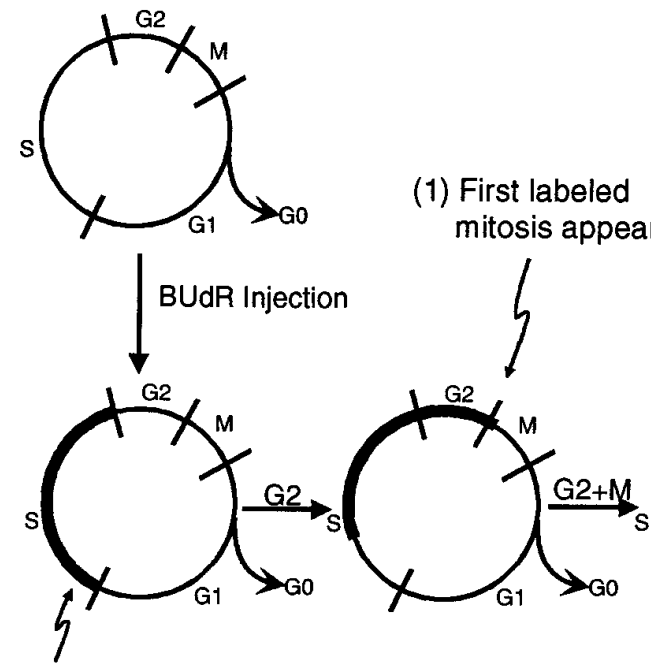

(0) BUdR injection labels cells in $S$

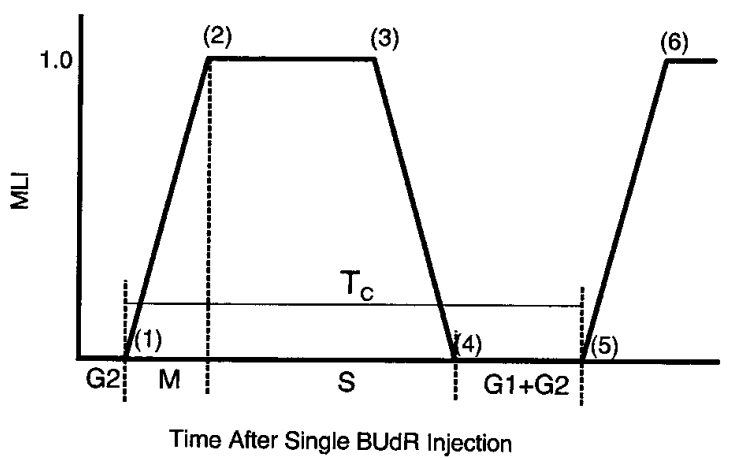

(2) All mitoses are labeled
(3) First unlabeled mitosis appears
(4) last labeled

mitosis leaves $M$
BUdR-Labeled Unlabeled 

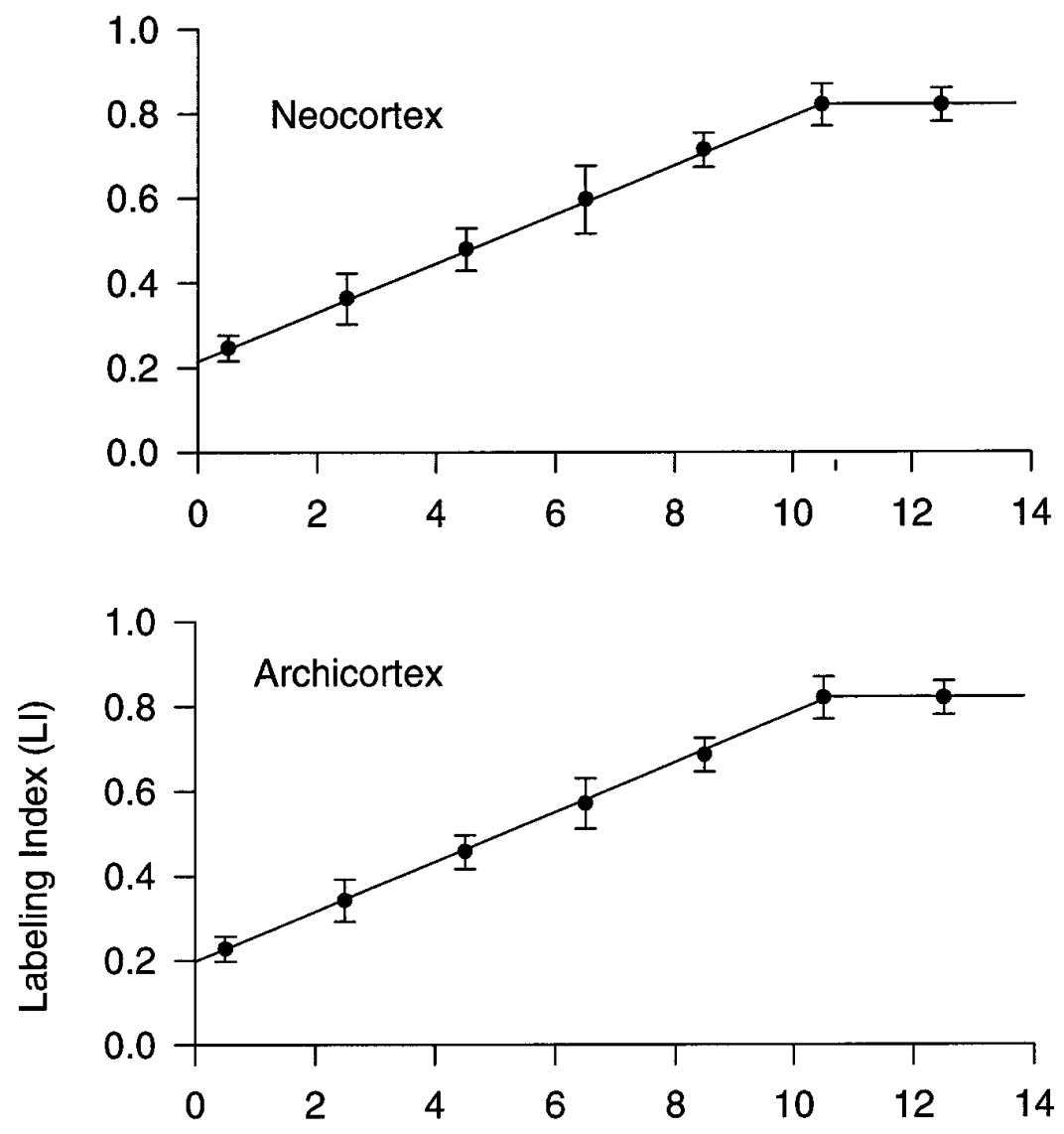

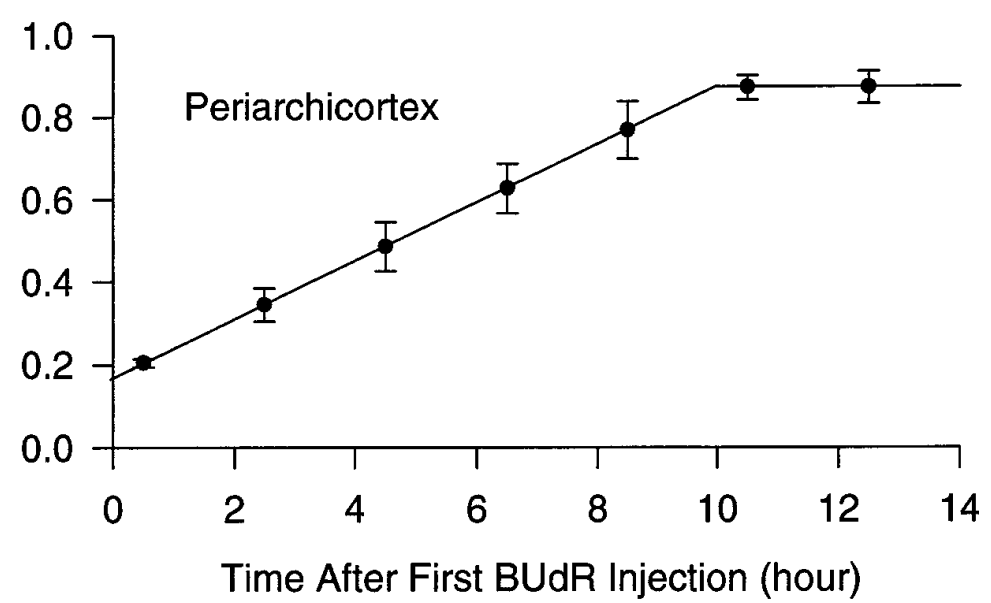

Figure 4. Graphs of LI of the developing cortex of the E14 mouse using the BUdR CLM. LI increases linearly until all proliferating cells (GF) have been labeled; labeling of GF occurs at a time equal to $\mathrm{T}_{\mathrm{C}}-\mathrm{T}_{\mathrm{S}}$. The labeling index at the $y$-intercept corresponds to $\mathrm{T}_{\mathrm{S}} / \mathrm{T}_{\mathrm{C}} \times \mathrm{GF}$. The $y$-intercept and inflection of the curve are extrapolated from a least-squares fit slope from all data points (for a complete discussion, see Nowakowski et al., 1989). The values of all cell cycle parameters derived from these data are summarized in Table 1. $A$, Neocortex; $B$, archicortex; $C$, periarchicortex.
Figure 5. From the difference in these two $\mathrm{X}$-intercepts, $\mathrm{T}_{\mathrm{C}}$ was found to be $12.3 \mathrm{hr}$ in the neocortex, $12.1 \mathrm{hr}$ in the archicortex, and $12.2 \mathrm{hr}$ in the periarchicortex. In all three cortical subdivisions, the close temporal spacing of the data points provides a high level of confidence that these estimates are precise to within $\pm 0.5 \mathrm{hr}$.

$\mathrm{T}_{\mathrm{S}}$ was estimated by the distance on the abscissa from the point when the first labeled mitotic figure appeared (as described in the previous paragraph) to the point when the first unlabeled mitotic figure appeared, which was determined by calculating the $100 \%$ intercept of the data points comprising the fall time of the PLM graphs in Figure 5. $\mathrm{T}_{\mathrm{S}}$ in the neocortex, archicortex, and periarchicortex were found to be $6.5,6.6$, and $6.5 \mathrm{hr}$, respectively.
$\mathrm{T}_{\mathrm{G} 2}$, i.e., the time after the injection at which the first labeled mitotic figure appeared, was measured as the distance along the abscissa from time 0 to the starting point of the first rise time of MLI (determined as described above). By this measurement, $\mathrm{T}_{\mathrm{G} 2}$ was found to be $0.9 \mathrm{hr}$ in neocortex and $0.8 \mathrm{hr}$ in both archicortex and periarchicortex.

$\mathrm{T}_{\mathrm{M}}$ was measured from the starting point of the first rise time of MLI until the time the MLI reached $100 \%$ (i.e., the lead labeled mitotic figure entered $G_{1}$ ). This is the duration of the first rise time and was calculated as the difference between the $\mathrm{X}$-intercept and the $100 \%$ intercept of the data points comprising the first rise time. $\mathrm{T}_{\mathrm{M}}$ was found to be $1.2 \mathrm{hr}$ in the neocortex, 1.4 $\mathrm{hr}$ in the archicortex, and $1.3 \mathrm{hr}$ in the periarchicortex. 


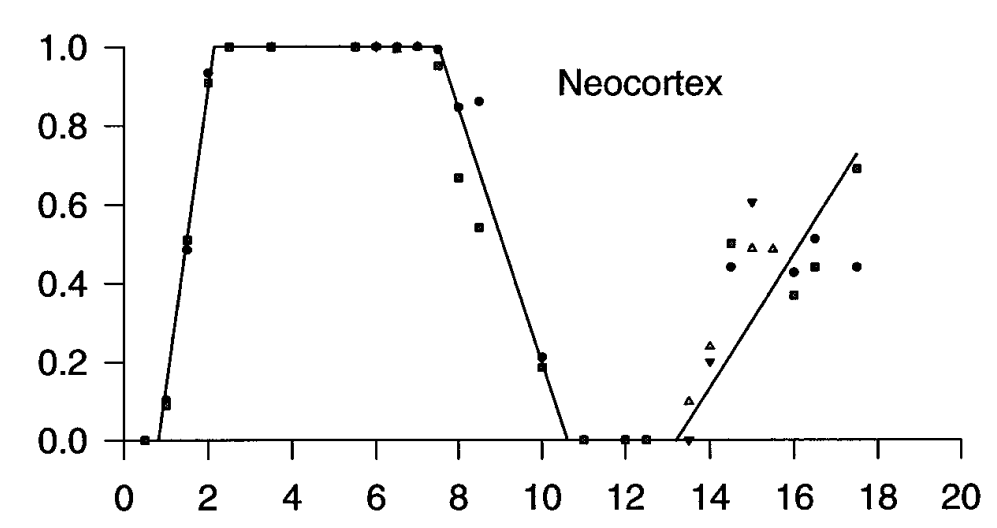

Figure 5. Graphs of the MLI of the developing cortex of the E14 mouse after a single injection of BUdR. MLI was calculated for each section and averaged for each fetus and then averaged for each litter; data for each litter (2-4 fetuses) were then plotted as a function of time after the single BUdR injection. The length of each phase of the cell cycle was determined from this plot as shown. Data points in the three different shapes (i.e., square, circle, triangle, and inverted triangle) at single time points represent data from different litters belonging to different experimental groups (see Materials and Methods). Note that in some cases the plotted data points from the different experimental groups fall exactly on top of one another and, hence, obscure the existence of the different shapes; this most frequently occurs for data across the $100 \%$ plateau. The location and length of the rise and fall phases were obtained using a linear least-squares fit to the data points that are clearly on the rising or falling phase, respectively. The values of all cell cycle parameters were derived from these data according to the methods illustrated in the graph in the bottom left corner in Figure 3 and are summarized in Table 1. $A$, Neocortex; $B$, archicortex; $C$, periarchicortex.

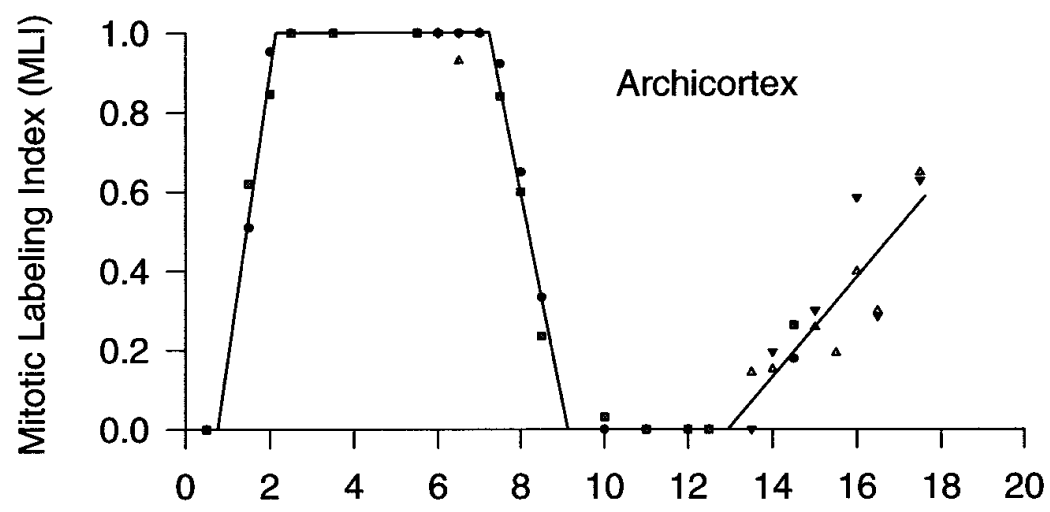

On the basis of the relationship, $\mathrm{T}_{\mathrm{G} 1}=\mathrm{T}_{\mathrm{C}}-\left(\mathrm{T}_{\mathrm{S}}+\mathrm{T}_{\mathrm{G} 2}+\mathrm{T}_{\mathrm{M}}\right)$, $\mathrm{T}_{\mathrm{G} 1}$ was found to be $3.7 \mathrm{hr}$ in the neocortex, $3.4 \mathrm{hr}$ in the archicortex, and $3.6 \mathrm{hr}$ in the periarchicortex.

\section{Differences in the rise and fall times of MLI}

In each of these three different cortical subdivisions it was also apparent that the duration of the rise time, i.e., the time needed for the lead cell of the labeled cohort to enter and traverse $\mathrm{M}$ phase completely, was different from the duration of the fall time, i.e., the time needed for the trailing cell of the same labeled cohort to traverse and exit $M$ phase (Fig. 5 and Table 2). The difference between the fall and rise times was $2.11 \mathrm{hr}$ in the neocortex, $0.29 \mathrm{hr}$ in the archicortex, and $1.52 \mathrm{hr}$ in the periarchicortex or $16.1 \%$ of the mean $\mathrm{T}_{\mathrm{C}}$ in the neocortex, $2.2 \%$ in the archicortex, and $12.4 \%$ in the periarchicortex. Although the rise

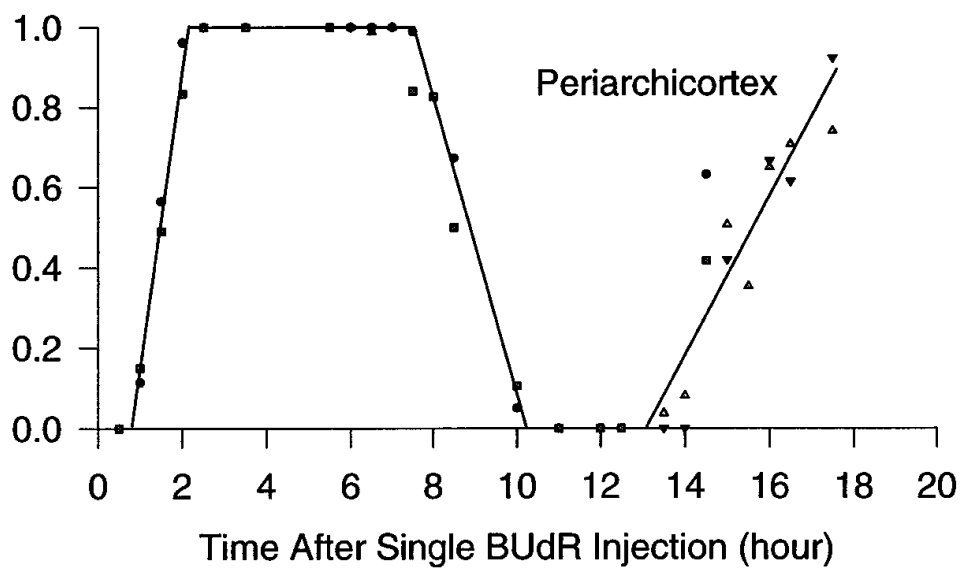

time of the second cell cycle was not followed to its end, it was obvious from its slope that it was greater than the fall time of the first cell cycle. Therefore, based on measurements of the rise and fall times of the first cell cycle, it can reasonably be assumed that the fall time for the second cell cycle would be even greater.

\section{DISCUSSION}

The results presented here provide, for the first time, measurements of maximum and minimum lengths of $\mathrm{T}_{\mathrm{C}}$ in the cortical PVE. The CLM gives an estimate for a maximum value of $T_{C}$ because it is derived from the detection of an inflection point in the slope of the rising LI. This inflection point corresponds to the time required to label the entire proliferative population and occurs when the last (or slowest cycling) proliferating cell that was 
Table 2. Differences in the rise and fall times of MLI in subdivisions of the E14 mouse cortex

\begin{tabular}{lllll}
$\begin{array}{l}\text { Brain } \\
\text { subdivisions }\end{array}$ & $\begin{array}{l}\text { Rise time }(\mathrm{hr}) \\
(0-100 \%)\end{array}$ & $\begin{array}{l}\text { Fall time }(\mathrm{hr}) \\
(100-0 \%)\end{array}$ & $\Delta(\mathrm{hr})$ & $\begin{array}{l}\% \text { of } \\
\text { mean } \mathrm{T}_{\mathrm{C}}\end{array}$ \\
\hline Neocortex & 1.21 & 3.32 & 2.11 & 16.1 \\
Archicortex & 1.38 & 1.67 & 0.29 & 2.2 \\
Periarchicortex & 1.32 & 2.85 & 1.52 & 12.4 \\
\hline
\end{tabular}

not labeled by the first injection enters the $\mathrm{S}$ phase and becomes labeled (see Nowakowski et al., 1989). In contrast, the PLM method gives an estimate of the minimum value of $T_{C}$ because it detects the time required for the first (or fastest cycling) proliferating cell to transit the entire cell cycle and enter $\mathrm{M}$ phase for a second time (Kauffman, 1968; Hoshino et al., 1973; Hamilton and Dobbin, 1983a,b). The difference between the maximum and minimum estimates of $T_{C}$ is an estimate of the range in $T_{C}$ for the slowest versus fastest cycling cells. In each of the three cortical subdivisions of E14 mouse, the range of $\mathrm{T}_{\mathrm{C}}$ was only a small proportion of the mean, i.e., $13.3 \%( \pm 6.7 \%)$ in the neocortex, $16.7 \%( \pm 8.3 \%)$ in the archicortex, and $1.5 \%( \pm 0.7 \%)$ in the periarchicortex. This relatively small range indicates that the difference in $\mathrm{T}_{\mathrm{C}}$ for the fastest versus the slowest cycling cells is only a small proportion of the total $T_{C}$. In other words, the transit time of the entire PVE population through the cell cycle is relatively homogeneous.

We have confirmed the range estimates by using closely spaced intervals for the PLM to provide a direct measurement of the intracycle variation. In theory, if cells in a homogeneous proliferative population progress through the cell cycle at a constant rate, the amount of time required for the MLI to rise from 0 to $100 \%$, i.e., the rise time, and the time required to fall from 100 to $0 \%$, i.e., the fall time, will be equal. However, if some labeled cells cycle more quickly than unlabeled cells (or vice versa) there will be "mixing" of the labeled and unlabeled populations as they progress through the cell cycle. The amount of mixing will be large if the range of cycling times is large and, conversely, small if the range of cycling times is small. We found that for the three cortical subdivisions, the fall time was between 2.2 and $16.1 \%$ longer than the rise time (Table 2), indicating that some, but not a great deal of, mixing occurs. The range estimates and the rise/fall time differences agree quite well, and averaging the two estimates from the two methods yields a range of $T_{C}$ of $14.7 \%$ of the mean $T_{C}$ in the neocortex, $9.4 \%$ in the archicortex, and $6.9 \%$ in the periarchicortex. It is not clear whether the differences between cortical subdivisions may be significant (compare Tables 1 and 2), but the overall mean for both methods and all three cortical subdivisions is $\sim 10 \%$ of the mean $\mathrm{T}_{\mathrm{C}}$ (or $\mathrm{T}_{\mathrm{C}} \pm 5 \%$ ).

The difference between the rise and fall times is readily apparent in the graphs published in a previous study using the PLM method (see Fig. 2 and Table 3 in Hoshino et al., 1973). Although these authors did not comment on this difference, we have estimated the difference between the fall and rise times from the published graphs of Hoshino et al. (Hoshino et al., 1973) and obtained a value of $2.2 \mathrm{hr}$ or $14.2 \%$ of $\mathrm{T}_{\mathrm{C}}$ for the $\mathrm{E} 13$ neocortex. This agrees remarkably well with our estimate of $14.7 \%$ at E14. In addition, it is also apparent from these data that the fall times, in particular, lengthen as development proceeds, i.e., the fall time at E13 is longer than that at E10 and shorter than that at E17, which parallels the progressive lengthening of $\mathrm{T}_{\mathrm{C}}$ during development. Again, measuring from the graphs of Hoshino et al. (1973), it is
Table 3. Differences in the rise and fall times of MLI in E10, E13, and E17 mouse telencephalon (calculated from Hoshino et al., 1973)

\begin{tabular}{lclllc}
$\begin{array}{l}\text { Gestation } \\
\text { day }\end{array}$ & $\mathrm{T}_{\mathrm{C}}(\mathrm{hr})$ & $\begin{array}{l}\text { Rise time }(\mathrm{hr}) \\
(0-100 \%)\end{array}$ & $\begin{array}{l}\text { Fall time }(\mathrm{hr}) \\
(100-0 \%)\end{array}$ & $\Delta(\mathrm{hr})$ & $\%$ of $\mathrm{T}_{\mathrm{C}}$ \\
\hline 10 & 7.0 & 0.8 & 1.2 & 0.4 & 5.7 \\
13 & 15.5 & 0.8 & 3.0 & 2.2 & 14.2 \\
17 & 26.0 & 0.8 & 5.0 & 4.2 & 16.2 \\
\hline
\end{tabular}

clear that both $\mathrm{T}_{\mathrm{C}}$ and the range of $\mathrm{T}_{\mathrm{C}}$ lengthen as cortical development proceeds (Table 3 ), and that the range of intracycle variation also increases from 5.7 to $16.2 \%$, i.e., approximately threefold. Recent studies have shown that $\mathrm{T}_{\mathrm{C}}$ of the PVE in the developing neocortex of the mouse lengthens from $8 \mathrm{hr}$ per cell cycle at E11 to $\sim 20 \mathrm{hr}$ at E17, and that most of this lengthening is a result of a fourfold increase in $\mathrm{T}_{\mathrm{G} 1}$ (Caviness et al., 1995). Thus, it is likely that most of the increased variability of $T_{C}$ is a result of an increase in the variability in $\mathrm{T}_{\mathrm{G} 1}$. This is supported by the fact that the slope of the second rise time (Fig. 5) is even less than that of the first fall time.

PLM data with closely timed samples can also be used to estimate the "purity" of the population in terms of $\mathrm{T}_{\mathrm{C}}$. This is because a proliferative population that contains a mixture of cells with significantly different $T_{C}$ values would produce a PLM graph with predictable deviations from the "ideal" graph obtained if a proliferative population contains a population of cells with identical $\mathrm{T}_{\mathrm{C}}$ values. Two ideal graphs produced by two different pure populations containing either only slow cycling cells $(10 \mathrm{hr} / \mathrm{cycle})$ or only fast ( $5 \mathrm{hr} /$ cycle) are shown in Figure $6, A$ and $B$, respectively. In both cases, the only data points in the plot that differ from either 0 or $100 \%$ are those that occur during the time needed to make the transition from 0 to $100 \%$ or back again, i.e., on the rising or falling phases, respectively. In addition, the rising and falling phases are of identical length. In contrast, the type of plot that would be obtained if there were either a 90:10 mixture of slow and fast cycling cells (Fig. 6C) or a 10:90 mixture (Fig. 6D) contains data points that differ from 0 or $100 \%$ in predictable additional places. These differences can be used as a sensitive method to detect "impurities" consisting of small proportions of cells with different cell cycle parameters. For example, the diagnostic features of a small proportion of slow moving cells mixed in with an otherwise homogenous population of fast cycling cells can be seen in the 90:10 mixture of fast:slow cycling cells (Fig. 6C). This mixture would be characterized by two features: (1) the presence of a transient drop from the $100 \%$ plateau (Fig. $6 C$, arrow) as the fast cycling cells pass first out of $\mathrm{M}$ and then reenter $\mathrm{M}$; and (2) the presence of "shoulders" at both the beginning of the rise time and end of the fall time (Fig. 6C, arrowheads). In contrast, the diagnostic features of a small proportion of fast cycling cells mixed in with an otherwise homogenous population of fast cycling cells can be seen in the 10:90 mixture shown (Fig. $6 D$ ). This mixture would also be characterized by two features as indicated by the arrow and arrowheads in Figure $6 D$ and explained further in the legend to Figure 6. Within reason, similar deviations from the ideal plots would be obtained for cells cycling at relative rates other than the ones that we have used for the illustration in Figure 6 and for other proportions of fast:slow cells. The important point in terms of our data are that the PLM graphs obtained from our data (Fig. 5) have none of these diagnostic features reflecting presence of either fast or slow cycling cells. For the neocortex, the only data point that may reflect the presence of 
"Slow" Cycling Population

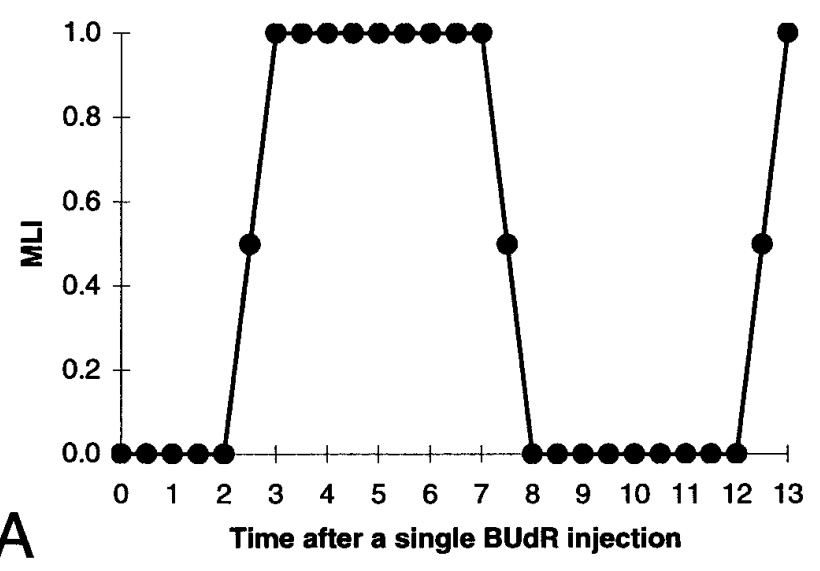

90\% Slow Cycling Population $+10 \%$
Fast Cycling Population

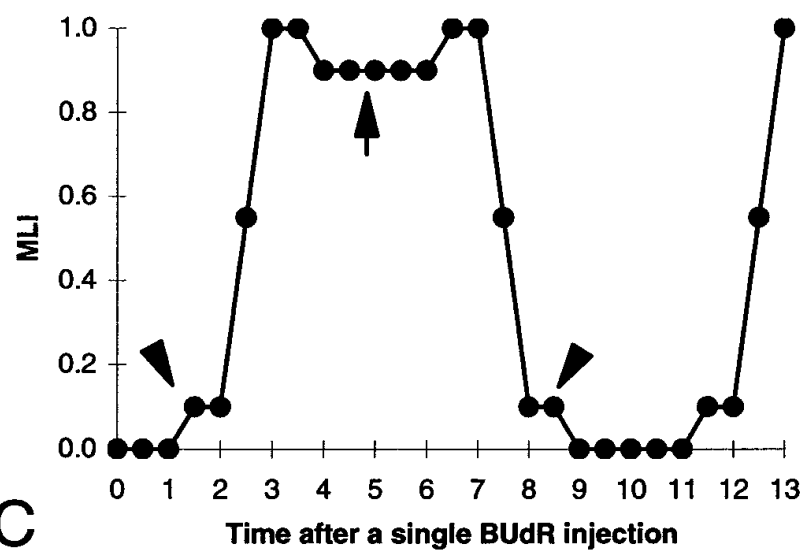

"Fast" Cycling Population

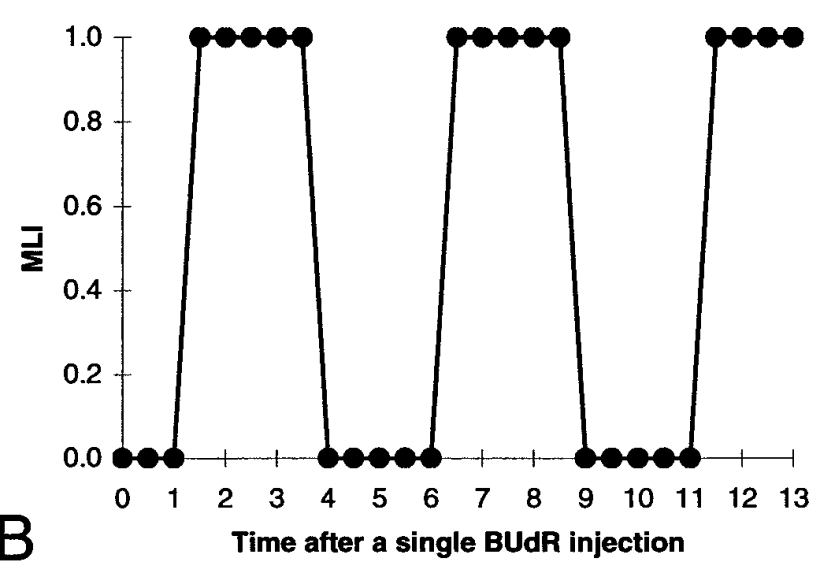

\section{0\% Fast Cycling Population + $10 \%$ Slow Cycling Population}

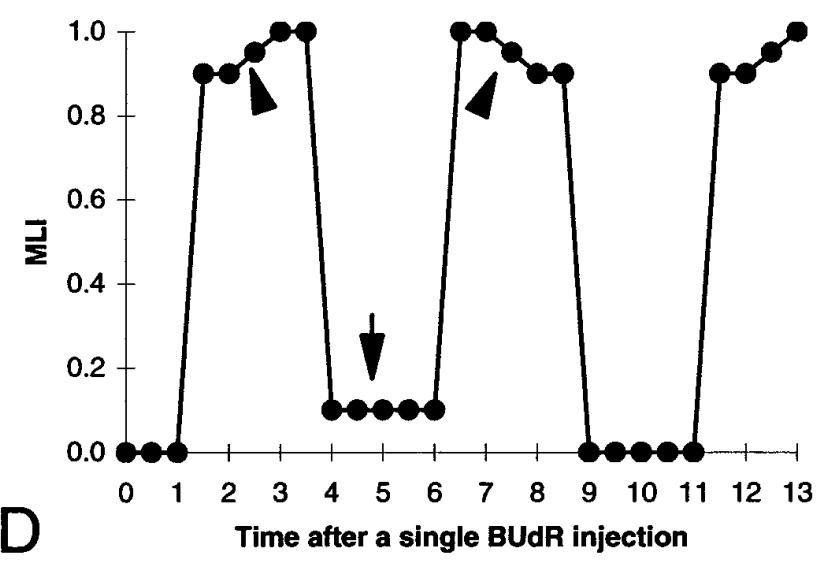

Figure 6. Predicted graphs of the MLI for hypothetical proliferative populations. $A, B$, Pure homogeneous populations of slow $(A)$ and fast $(B)$ cycling cells. $\mathrm{T}_{\mathrm{C}}$ of the slow cycling population is $10 \mathrm{hr}$, and $\mathrm{T}_{\mathrm{C}}$ of the fast cycling population is $5 \mathrm{hr}$. Note that both the 0 and the $100 \%$ "plateau" phases in both pure populations are flat. $C, D$, Graphs of MLIs in heterogenous populations containing $90 \%$ slow with $10 \%$ fast cycling cells $(C)$ and $90 \%$ fast and $10 \%$ slow cycling cells $(D)$. Transient deviations occur during both the 0 and the $100 \%$ plateau phases (arrows and arrowheads), as well as at the beginnings and ends of the rising and falling phases.

cell cycling at different rates is a slight decrease in the MLI during the $100 \%$ plateau at $6.5 \mathrm{hr}$ postinjection in a single specimen; however, there was no such decrease at either 6.0 or $7.0 \mathrm{hr}$ or at any other time point across the entire $100 \%$ plateau. For the neocortex, of the 1422 mitotic figures counted during the $100 \%$ plateau, only $6(0.4 \%)$ were unlabeled; this places an upper limit on the proportion of fast cycling cells. In addition, neither of the shoulders on the rise and fall time curves (Fig. 6A,B) are present on the plots shown in Figure 5. Note that we used closely spaced time points $(<0.5 \mathrm{hr})$ and that the data points on the rise time are essentially collinear, and thus the absence of the diagnostic shoulders can be determined with considerable confidence. Taken together, the flatness of the $100 \%$ plateau and the sharpness of the transitions indicate that the proportion of the cell population for which $\mathrm{T}_{\mathrm{C}}$ deviates significantly from the estimated ranges that we have measured is probably $<1 \%$. This is more than an order of magnitude smaller than previously estimated from the CLM alone (Nowakowski et al., 1989). In the context of the possible existence within the cortical PVE of two populations with markedly dissim- ilar cell cycle kinetics from the mean, one such population must comprise $\sim 99 \%$ of the total population, and the other, if it exists, is only $\sim 1 \%$ of the total. This seems to be true for all three cortical regions.

If $99 \%$ of the proliferative population is cycling within a narrow range, then any two cells that are in the same phase of the cell cycle at any given time will be in approximately the same phase of the cell cycle one cell cycle later. Thus, at least in terms of the cell cycle, the PVE is relatively homogeneous. Most important, there is relative homogeneity of $\mathrm{T}_{\mathrm{C}}$ in all three cortical subdivisions that we studied. This is of particular interest because in the archicortex both neurons and glia must be generated by the PVE (Nowakowski and Rakic, 1981), whereas in the neocortex it is very likely that the PVE generates only neurons (Nowakowski and Rakic, 1981; Takahashi et al., 1995a,b). The fact that relative synchrony and a narrow range of $\mathrm{T}_{\mathrm{C}}$ exist in three subdivisions of the cortex at E14, despite the fact that these subdivisions have different cell lineage potentials, indicates that the neuronal and glial lineages do not differ dramatically in cell cycle characteristics. It was of 
interest that $\mathrm{T}_{\mathrm{C}}$ for PVE and the SPP in the neocortex are also similar (Takahashi et al., 1995b), suggesting that $\mathrm{T}_{\mathrm{C}}$ homogeneity may be a general feature of the proliferative population in CNS development. The significance of a homogeneous $T_{C}$ for a proliferative population can best be appreciated if the likely behavior of two daughter cells that are the product of a single mitotic division is considered. If both of these two daughter cells continue to proliferate, they will start through the cell cycle at the beginning of $\mathrm{G}_{1}$ at approximately the same rate. One cell cycle later, these same two daughter cells will divide at the same time and four daughter cells will be produced; these four daughter cells will also be in approximately the same phase, i.e., at the beginning of $\mathrm{G}_{1}$, and may progress through the next cell cycle at approximately the same speed. If this continues for several cell cycles, small clones of contiguous cells will be produced. Therefore, we would predict that clonally related cells will tend to move through the cell cycle together, that each clone will form a small contiguous cluster in the PVE, and that, as a result, the PVE is a mosaic of small clusters of clonally related cells. This prediction has been confirmed using a retroviral cell lineage tracing technique (Cai et al., 1997).

\section{REFERENCES}

Angevine Jr JB, Sidman RL (1961) Autoradiographic study of cell migration during histogenesis of cerebral cortex in the mouse. Nature 192:766-768.

Cai L, Hayes NL, Nowakowski RS (1993) Comparison of the cumulative S-phase labeling method and the percent labeled mitoses method in the developing cerebral cortex. Soc Neurosci Abstr 19:30.

Cai L, Hayes NL, Nowakowski RS (1997) Synchrony of clonal cell proliferation and contiguity of clonally related cells: production of mosaicism in the ventricular zone of developing mouse neocortex. J Neurosci 17:2088-2100.

Caviness Jr VS (1982) Neocortical histogenesis in normal and reeler mice: a developmental study based upon $\left[{ }^{3} \mathrm{H}\right]$ thymidine autoradiography. Dev Brain Res 4:293-302.

Caviness Jr VS, Sidman RL (1973) Time of origin of corresponding cell classes in the cerebral cortex of normal and reeler mutant mice: an autoradiographic analysis. J Comp Neurol 148:141-151.

Caviness Jr VS, Takahashi T, Nowakowski RS (1995) Numbers, time and neocortical neuronogenesis: a general developmental and evolutionary model. Trends Neurosci 18:379-383.

Hamilton E, Dobbin J (1983a) The percentage labeled mitoses technique shows the mean cell cycle time to be half its true value in carcinoma TY. I. $\left[{ }^{3} \mathrm{H}\right]$ thymidine and vincristine studies. Cell Tissue Kinet 16:473-482.

Hamilton E, Dobbin J (1983b) The percentage labelled mitoses technique shows the mean cell cycle time to be half its true value in carcinoma NT. II. $\left[{ }^{3} \mathrm{H}\right]$ deoxyuridine studies. Cell Tissue Kinet 16:483-492.

Hoshino K, Matsuzawa T, Murakami U (1973) Characteristics of the cell cycle of matrix cells in the mouse embryo during histogenesis of telencephalon. Experimental Cell Res 77:89-94.

Kauffman SL (1968) Lengthening of the generation cycle during embryonic differentiation of the mouse neural tube. Exp Cell Res 49:420-424.

Levitt P, Cooper ML, Rakic P (1981) Coexistence of neuronal and glial precursor cells in the cerebral ventricular zone of the fetal monkey: an ultrastructural immunoperoxidase analysis. J Neurosci 1:27-39.

Miller MW, Nowakowski RS (1988) Use of bromodeoxyuridine immunohistochemistry to examine the proliferation, migration and time of origin of cells in the central nervous system. Brain Res 457:44-52.

Misson J-P, Edwards MA, Yamamoto M, Caviness Jr VS (1988a) Mitotic cycling of radial glial cells of the fetal murine cerebral wall: a combined autoradiographic and immunohistochemical study. Dev Brain Res 38:183-190.

Misson J-P, Edwards MA, Yamamoto M, Caviness Jr VS (1988b) Identification of radial glial cells within the developing murine central nervous system: studies based upon a new immunochemical marker. Dev Brain Res 44:95-108.

Nowakowski RS, Rakic P (1981) The site of origin and route and rate of migration of neurons to the hippocampal region of the rhesus monkey. J Comp Neurol 196:129-54.

Nowakowski RS, Lewin SB, Miller MW (1989) Bromodeoxyuridine immunohistochemical determination of the lengths of the cell cycle and the DNA-synthetic phase for an anatomically defined population. J Neurocytol 18:311-318.

Rakic P (1972) Mode of cell migration to the superficial layers of fetal monkey neocortex. J Comp Neurol 145:61-84.

Reznikov K, van der Kooy D (1995) Variability and partial synchrony of the cell cycle in the germinal zone of the early embryonic cerebral cortex. J Comp Neurol 360:536-554.

Steel GG (1977) Growth kinetics of tumors. Oxford, UK: Clarendon.

Takahashi T, Nowakowski RS, Caviness Jr VS (1992) BUdR as an S-phase marker for quantitative studies of cytokinetic behaviour in the murine cerebral ventricular zone. J Neurocytol 21:185-197.

Takahashi T, Nowakowski RS, Caviness Jr VS (1993) Cell cycle parameters and patterns of nuclear movement in the neocortical proliferative zone of the fetal mouse. J Neurosci 13:820-833.

Takahashi T, Nowakowski RS, Caviness Jr VS (1995a) The cell cycle of the pseudostratified ventricular epithelium of the embryonic murine cerebral wall. J Neurosci 15:6046-6057.

Takahashi T, Nowakowski RS, Caviness Jr VS (1995b) Early ontogeny of the secondary proliferative population of the embryonic murine cerebral wall. J Neurosci 15:6058-6068.

Theiler K (1972) The house mouse. Development and normal stages from fertilization to 4 weeks of age. Berlin: Springer.

Waechter RV, Jaensch B (1972) Generation times of the matrix cells during embryonic brain development: an autoradiographic study in rats. Brain Res 46:235-250. 